\title{
Use of Biologic Agents in Ocular Manifestations of Rheumatic Disease
}

\author{
Courtney L. Kraus and Susan M. Culican \\ Department of Ophthalmology and Visual Sciences, Washington University School of Medicine, St. Louis, \\ MO 63110, USA \\ Correspondence should be addressed to Courtney L. Kraus, krausc@vision.wustl.edu
}

Received 1 October 2011; Accepted 31 October 2011

Academic Editor: Jozélio Freire de Carvalho

Copyright ( 52012 C. L. Kraus and S. M. Culican. This is an open access article distributed under the Creative Commons Attribution License, which permits unrestricted use, distribution, and reproduction in any medium, provided the original work is properly cited.

\begin{abstract}
Biologic agents have dramatically shifted the treatment paradigm for rheumatic disease. Use of these agents can decrease disease burden, allow the patient to be weaned from corticosteroids, and reduce the likelihood of relapse. Eye disease associated with rheumatic conditions may present with a wide range of signs and symptoms. This coexisting pathology should not be overlooked and should be considered a reason for initiation or continuation of biologic therapy. Additionally, many of the ocular manifestations of rheumatic disease respond preferentially to specific targeting molecules. This paper summarizes the available studies on the use, efficacy, and safety of biologic agents in the treatment of ocular manifestations of rheumatic disease.
\end{abstract}

\section{Introduction}

Eye disease associated with rheumatic conditions may present with a wide range of signs and symptoms. The treating physician must be careful not to overlook ocular manifestations, as they can be quite subtle. Dry eye syndrome, acute and chronic anterior uveitis, panuveitis or vitritis, scleritis, keratitis, retinal vasculitis, and ischemic optic neuropathy represent ocular disorders frequently associated with rheumatic diseases. In patients presenting with nonspecific signs and symptoms, ocular findings may be the only clue to the final diagnosis. Alternatively, in patients with long-standing rheumatic disease, ophthalmic flares may suggest further deterioration or relapse.

The mainstay of management of inflammatory ocular conditions has been topical agents with occasional oral corticosteroid use. However, for some conditions these therapies are often inadequate. Biologic therapies (Table 1) have demonstrated efficacy in the control of many of the primary manifestations of rheumatic disease. Their targeted use in the ocular manifestations of rheumatic disease has not been as extensively studied. This paper seeks to compile the available reports on the use, efficacy, and safety of biologic agents in the treatment of ocular symptoms of rheumatic disease.

\section{Adamantiades-Behçet's Disease}

Ocular symptoms occur in $43-72 \%$ of AdamantiadesBehçet's disease (ABD) patients and affect males more commonly than females. The classic appearance is that of an anterior uveitis with a sterile hypopyon; however, presentations more often feature a posterior or diffuse uveitis with accompanying retinal vasculitis [1].

$\mathrm{ABD}$ is an aggressive, sight-threatening disease that requires immunosuppressive therapy to avoid vision loss. TNF- $\alpha$ antagonists are the preferred first line agent for treatment of ABD. They have proven successful in controlling symptoms, reducing ocular relapses, and significantly decreasing the daily dose of corticosteroids $[2,3]$. Infliximab has emerged as the foremost agent with several prospective studies demonstrating remission of anterior and posterior segment inflammation, resolution of macular edema, and successful control of uveitis refractory to previous therapy $[4,5]$. Among the anti-TNF- $\alpha$ agents, infliximab has been 
TABLE 1: Biologic agents.

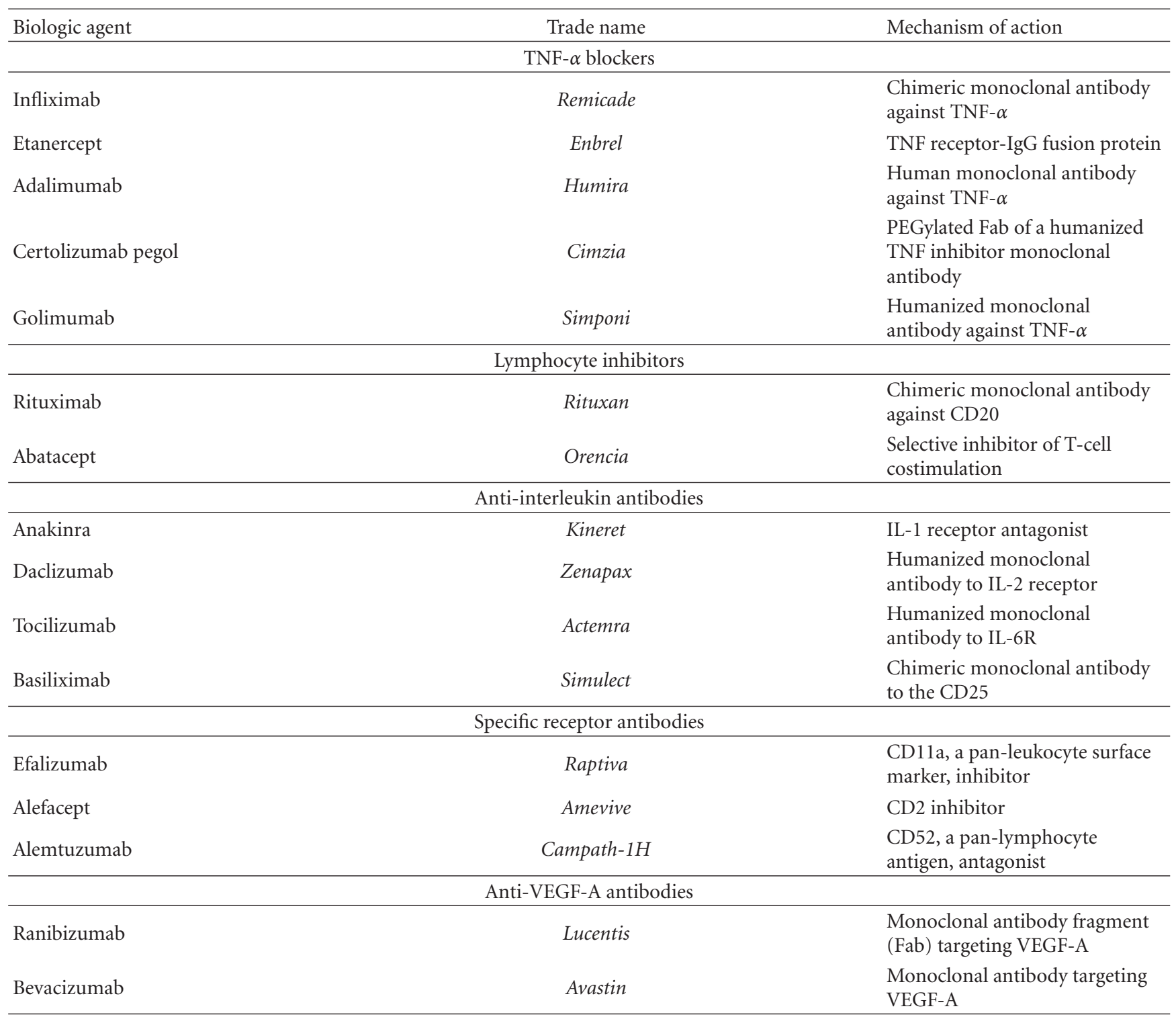

shown to achieve the best control of ocular signs and symptoms $[1,6]$.

While not as extensively studied, several reports have suggested etanercept and adalimumab are effective in controlling ABD disease severity [7, 8]. Treatment with etanercept achieves a greater response in ocular manifestations of ABD over other complications such as oral ulcers, arthritis, and skin lesions [9]. Adalimumab may induce and maintain sustained remission of refractory ocular inflammation in about $90 \%$ of patients [10].

Among the other biologic agents, rituximab has shown success in retinal vasculitis associated with ABD [11]. A case report describing the effective management of $\mathrm{ABD}$ with anakinra did not address ocular symptoms [12]. The ability of therapy targeting interleukin activity to reduce disease burden suggests IL- $1 \beta$ is a mediator of inflammation in ABD and may effectively treat its ocular manifestations.

\section{Rheumatoid Arthritis}

Rheumatoid arthritis (RA) gives rise to significant eye disease in $15-30 \%$ of affected patients. Characteristic presentations include keratoconjunctivitis sicca (KCS), stromal keratitis, sclerosing keratitis, scleritis, and episcleritis. KCS is by far the most common ocular manifestation (11.6\%), followed by episcleritis and scleritis [13].

Dry eyes can be significantly disabling and difficult to treat. Aggressive lubrication, punctal plugs, autologous serum drops, prednisolone drops, and topical cyclosporine make up the ophthalmologist's armamentarium. This localized approach satisfactorily controls most patients; however, systemic steroids and increased methotrexate are occasionally necessary. Although not sight threatening, symptoms can exert an increasing burden as the disease progresses or increases in severity. KCS patients have various degrees 
of health-related quality of life impairment [14]. Although unconventional, initiation of infliximab in otherwise quiescent RA has successfully controlled KCS symptoms [15]. Evidence suggests that the indirect costs of KCS actually may outweigh the expense of biologic treatment [16].

Reinforcing the importance of TNF- $\alpha$ in the control of corneal inflammation, the TNF- $\alpha$ antagonists, infliximab, adalimumab, and etanercept have been shown to be effective therapies for RA-associated keratitis. They have shown differing levels of efficacy [17-19]. Infliximab has been shown to be the most effective agent to control RA-associated keratitis $[20,21]$. Rituximab has been used successfully in the treatment of severe peripheral ulcerative keratitis (PUK) demonstrating prior resistance to anti-TNF agents [22]. However, a case of bilateral PUK following treatment with rituximab has been reported. Causation was not established [23].

Necrotizing scleritis is the most destructive form of scleritis and has considerable ocular morbidity. In patients with RA, it is associated with a high mortality, especially when not treated with immunosuppressants. Anti-TNF- $\alpha$ agents have the most evidence supporting their use and efficacy in scleritis. Certolizumab pegol has been shown to control scleritis in a patient with RA who had failed other TNF- $\alpha$ antagonists [24].

Inflammation control in the eyes of RA patients remains a challenge. Head to head comparison trials of the many biologics have not been completed. A large review of several individual studies indicated that TNF- $\alpha$ antagonists (certolizumab, adalimumab, infliximab, etanercept), the B-cell inhibitor (rituximab), and the IL-6 blocker (tocilizumab) are superior to T-cell costimulation inhibitor (abatacept) and the IL-1 blocker (anakinra). However, none of the comparisons between these biologics reached statistical significance [25].

\section{Juvenile Idiopathic Arthritis}

Uveitis occurs in $10 \%-15 \%$ of patients with juvenile idiopathic arthritis (JIA) and represents the primary cause of uveitis in childhood. Contrary to the red painful eye seen in adults with uveitis; the inflammation seen in children is often asymptomatic and bilateral, with an indolent chronic course. Severe vision loss, even blindness, occurs in an unacceptably high percentage of patients with one-quarter of children with JIA becoming blind in one eye [26].

Topical steroids are the first line of therapy, but only around $40 \%$ of patients respond to such treatment. The associated risks of increased intraocular pressure and cataract are particularly unappealing in a pediatric population. An investigation into the effectiveness of the three most popular anti-TNF- $\alpha$ agents, etanercept, infliximab, and adalimumab, found infliximab to be more effective than etanercept. No statistically significant conclusion was drawn regarding adalimumab [27]. Infliximab, however, was found to have a high rate of side effects in a prospective study [28]. The preferred anti-TNF- $\alpha$ agent is adalimumab, which is more effective against uveitis than etanercept and better tolerated by children [29].

Use of biologic agents not targeting TNF- $\alpha$ has only recently been published. Rituximab has reported efficacy in patients refractory to treatment with TNF- $\alpha$ antagonists [30]. Preliminary studies of high-dose intravenous administration of IL-2 antagonist, daclizumab demonstrate a reduction in active inflammation in JIA-associated anterior uveitis [31]. In a prospective study of abatacept in cases refractory to anti-TNF- $\alpha$ treatment, all seven children exhibited decreased anterior segment inflammation. However, only one demonstrated complete resolution with this treatment [32]. A headto-head comparison of these newer agents has not been performed.

\section{Sjogren's Syndrome}

KCS, or severe dry eye, is the hallmark of Sjogren's syndrome (SS) and indicates an autoimmune attack on the lacrimal gland. Therapeutic options for the debilitating xerophthalmia are currently limited to symptomatic relief with aggressive artificial lubrication, autologous serum eye drops, topical cyclosporine, topical corticosteroids, and punctal occlusion.

Understanding the inflammatory cascade involved in SS suggests elevated levels of proinflammatory cytokines (e.g., IL- $1 \alpha$, IL- $1 \beta$, IL-6, TNF $\alpha$ ) and immunoactivators (e.g., ICAM-1, CD40, CD40 ligand) play a role the ocular symptoms [33]. Newer treatment strategies are targeting these pathways as therapeutic options. Preliminary studies of the anti-TNF- $\alpha$ agents were promising; however, a large randomized trial failed to demonstrate a difference in response between placebo and an infliximab-treated group [34]. Similarly, etanercept was also no more effective than placebo in a 12-week study [35].

While a recent double-blind, randomized, placebocontrolled trial indicated that rituximab is effective and safe in the treatment of patients with SS, ocular signs and symptoms were not among the measures demonstrating improvement with treatment [36]. A case report did report improvement in subjective and objective measures of xerophthalmia in 2 patients treated with rituximab [37].

\section{Seronegative Spondyloarthropathy}

The seronegative spondyloarthropathies, ankylosing spondylitis (AS), psoriatic arthritis (PsA), inflammatory bowel disease (IBD), and reactive arthritis (ReA) represent a group of diseases that share clinical, genetic, and pathological characteristics. They share an association with HLA-B27, an absence of positive rheumatoid factor (negative serostatus), and extra-articular features, such as involvement of eyes, skin, and genitourinary tract.

Anterior uveitis reportedly occurs in up to $30 \%$ of patients with AS. There is now accumulating evidence that targeted anti-TNF- $\alpha$ therapy is highly effective in spondyloarthritis [38]. Patients taking anti-TNF- $\alpha$ agents exhibited significantly reduced rates of recurrence of anterior uveitis in the major trials, with stronger protection afforded by infliximab and adalimumab [39, 40]. Other biologics have not shown as much promise; abatacept failed to show improvement in any outcome measures in one prospective study [41]. 
The classic triad of ReA includes arthritis, nongonococcal urethritis, and conjunctivitis. However, ocular manifestations may also include acute anterior uveitis. Current opinion is that because TNF- $\alpha$ drives the pathogenesis of reactive arthritis and suggests TNF- $\alpha$ antagonists will be efficacious therapeutic tools. Like AS, definitive studies are lacking but isolated case reports support the use of anti-TNF$\alpha$ agents [42, 43].

Biologic treatment of the uveitis associated with PsA, like the other seronegative spondyloarthropathies, centers on the anti-TNF- $\alpha$ therapies [44]. Evidence suggests infliximab provides the greatest response among the anti-TNF- $\alpha$ agents $[45,46]$.

Inflammatory bowel disease (IBD), like the other spondyloarthropathies, can be associated with an acute anterior uveitis. It also can present with a keratitis or scleritis. Successful control of the ocular inflammation has been seen in IBD patients using TNF- $\alpha$ antagonists [47]. Of the TNF$\alpha$ inhibiting therapies, etanercept is ineffective in controlling both the systemic symptoms of IBD and the associated uveitis [48].

\section{Relapsing Polychondritis}

Fifty-nine percent of patients with relapsing polychondritis (RP) have ocular components of their disease. The most common manifestation is scleritis, seen in $41 \%$ of patients; uveitis is seen in one-quarter of patients; conjunctivitis, episcleritis, keratitis, and retinal vasculitis are seen less frequently [49]. Immunosuppressive chemotherapy is usually required to successfully treat the ocular manifestations of RP, especially nodular and necrotizing scleritis [50]. Infliximab was shown to diminish ocular manifestations [51].

\section{Systemic Vasculitic Disease}

Giant cell arteritis (GCA) can cause an incredibly rapid total or near total loss of vision. Without prompt recognition and initiation of high-dose intravenous steroids, bilateral vision loss may result in up to $50 \%$ of individuals. Maintenance therapy with biologic agents is an attractive theory, as it would allow avoidance of chronic steroids and the associated morbidity. Studies of TNF- $\alpha$ antagonists have mixed results. Infliximab was not shown to be effective in a prospective randomized trial [52]. However, a case of reported steroidresistant GCA was treated successfully with adalimumab [53]. Rituximab was also effective in reducing inflammatory markers in a patient with GCA refractory to treatment with corticosteroids [54].

Ocular manifestations are very common in Wegener's granulomatosis (WG), affecting approximately half of patients. Scleritis, keratitis, orbital disease, and less commonly retinovasculitis or uveitis are all potential manifestations of WG [55]. The other ANCA-associated vasculitides, microscopic polyangiitis, and Churg-Strauss present much less frequently with ophthalmic complications. Reversal of vision loss was seen in a case of severe posterior scleritis in WG treated with infliximab [56]. Rituximab has emerged as an effective tool in treating ocular manifestations of WG [57, 58]. Recent evidence suggests it is equivalent to cyclophosphamide for the induction of remission, with particular efficacy at inducing remission in patients with relapsing disease [59]. It was shown to be superior to infliximab by a small prospective study [60].

\section{Anterior Uveitis Induced by Anti-TNF Agents}

As discussed above, extensive evidence supports the efficacy of TNF- $\alpha$ antagonists in the treatment of uveitis associated with rheumatologic disease. Paradoxically, use of these agents has been implicated to cause uveitis. Several anecdotal case reports suggested an association between use of these agents and development of uveitis [61]. Subsequently, a review of medication adverse event registries not only confirmed this observation but also suggested etanercept caused a greater number of reported uveitis cases compared to infliximab and adalimumab [62]. A retrospective review reported a frequency of 1 case per 100 patient-year for patients treated with a TNF- $\alpha$ antagonist for seronegative spondylopathy [63].

\section{Conclusion}

The last decade has seen a dramatic increase in the number and nature of biologic agents. We continue to expand our knowledge of rheumatologic disease and the role of the inflammatory cascade in the ocular manifestations of those diseases. Systemically, administered small molecular antibodies and antagonists have become valuable tools in the treatment of refractory ophthalmic symptoms of rheumatic disease. In certain cases, these agents can even be considered primary therapeutic options.

Recently, two humanized monoclonal antibodies targeting vascular endothelial growth factor-A (VEGF-A), ranibizumab (Lucentis) and bevacizumab (Avastin) have revolutionized the treatment of eye diseases such as agerelated macular degeneration. These agents are delivered via an intraocular injection and are effective and well tolerated [64]. Preliminary safety studies to evaluate toxicity of intravitreal injection of TNF $\alpha$ inhibitors have been performed in rabbits with experimental uveitis, with promising results [65, 66]. Future treatment of ocular manifestations of rheumatic disease will certainly build upon the documented efficacy of biologic agents and the ability to locally inject these antibodies and antagonists.

\section{Disclosure}

The authors have no financial interests or conflict of interests to disclose.

\section{References}

[1] F. R. Zakka, P. Y. Chang, G. P. Giuliari, and C. S. Foster, "Current trends in the management of ocular symptoms in Adamantiades-Behçet's disease," Clinical Ophthalmology, vol. 3, no. 1, pp. 567-579, 2009. 
[2] I. Tugal-Tutkun, A. Mudun, M. Urgancioglu et al., "Efficacy of infliximab in the treatment of uveitis that is resistant to treatment with the combination of azathioprine, cyclosporine, and corticosteroids in Behçet's disease: an open-label trial," Arthritis and Rheumatism, vol. 52, no. 8, pp. 2478-2484, 2005.

[3] M. Takamoto, T. Kaburaki, J. Numaga, Y. Fujino, and H. Kawashima, "Long-term infliximab treatment for Behçet's disease," Japanese Journal of Ophthalmology, vol. 51, no. 3, pp. 239-240, 2007.

[4] P. P. Sfikakis, N. Markomichelakis, E. Alpsoy et al., "Anti-TNF therapy in the management of Behçet's disease-review and basis for recommendations," Rheumatology, vol. 46, no. 5, pp. 736-741, 2007.

[5] P. P. Sfikakis, "Behçet's disease: a new target for anti-tumour necrosis factor treatment," Annals of the Rheumatic Diseases, vol. 61, supplement 2, pp. ii51-ii53, 2002.

[6] C. Evereklioglu, "Ocular Behçet disease: current therapeutic approaches," Current Opinion in Ophthalmology, vol. 22, no. 6, pp. 508-516, 2011.

[7] M. Accorinti, M. P. Pirraglia, M. P. Paroli, R. Priori, F. Conti, and P. Pivetti-Pezzi, "Infliximab treatment for ocular and extraocular manifestations of Behçet's disease," Japanese Journal of Ophthalmology, vol. 51, no. 3, pp. 191-196, 2007.

[8] M. Melikoglu, I. Fresko, C. Mat et al., "Short-term trial of etanercept in Behçet's disease: a double blind, placebo controlled study," Journal of Rheumatology, vol. 32, no. 1, pp. 98-105, 2005.

[9] B. Mushtaq, T. Saeed, R. D. Situnayake, and P. I. Murray, "Adalimumab for sight-threatening uveitis in Behçet's disease," Eye, vol. 21, no. 6, pp. 824-825, 2007.

[10] M. Melikoglu, Y. Özyazgan, I. Fresko et al., "The response of treatment resistant uveitis in Behçet's syndrome (BS) to a TNF- $\alpha$ blocker, etanercept: an open study," Arthritis \& Rheumatism, vol. 46, p. 181, 2002.

[11] L. Niccoli, C. Nannini, M. Benucci et al., "Long-term efficacy of infliximab in refractory posterior uveitis of Behçet's disease: a 24-month follow-up study," Rheumatology, vol. 46, no. 7, pp. 1161-1164, 2007.

[12] F. Davatchi, H. Shams, M. Rezaipoor et al., "Rituximab in intractable ocular lesions of Behcet's disease; randomized single-blind control study (pilot study)," International Journal of Rheumatic Diseases, vol. 13, no. 3, pp. 246-252, 2010.

[13] C. Botsios, P. Sfriso, A. Furlan, L. Punzi, and C. A. Dinarello, "Resistant Behçet disease responsive to anakinra," Annals of Internal Medicine, vol. 149, no. 4, pp. 284-286, 2008.

[14] C. Turesson, W. M. O’Fallon, C. S. Crowson, S. E. Gabriel, and E. L. Matteson, "Extra-articular disease manifestations in rheumatoid arthritis: incidence trends and risk factors over 46 years," Annals of the Rheumatic Diseases, vol. 62, no. 8, pp. 722727, 2003.

[15] P. Mertzanis, L. Abetz, K. Rajagopalan et al., "The relative burden of dry eye in patients' lives: comparisons to a U.S. normative sample," Investigative Ophthalmology and Visual Science, vol. 46, no. 1, pp. 46-50, 2005.

[16] M. Cordero-Coma, F. Anzaar, L. Sobrin, and C. S. Foster, "Systemic immunomodulatory therapy in severe dry eye secondary to inflammation," Ocular Immunology and Inflammation, vol. 15, no. 2, pp. 99-104, 2007.

[17] S. J. Bowman, Y. S. Pierre, N. Sutcliffe et al., "Estimating indirect costs in primary Sjögren's syndrome," Journal of Rheumatology, vol. 37, no. 5, pp. 1010-1015, 2010.

[18] I. I. Atchia, C. E. Kidd, and R. W. D. Bell, "Rheumatoid arthritis-associated necrotizing scleritis and peripheral ulcerative keratitis treated successfully with infliximab," Journal of Clinical Rheumatology, vol. 12, no. 6, pp. 291-293, 2006.

[19] M. Hernandez-Illas, E. Tozman, S. F. Fulcher, J. W. Jundt, J. Davis, and S. C. Pflugfelder, "Recombinant human tumor necrosis factor receptor Fc fusion protein (Etanercept): experience as a therapy for sight-threatening scleritis and sterile corneal ulceration," Eye and Contact Lens, vol. 30, no. 1, pp. 2-5, 2004.

[20] A. Galor, V. L. Perez, J. P. Hammel, and C. Y. Lowder, "Differential effectiveness of etanercept and Infliximab in the treatment of ocular inflammation," Ophthalmology, vol. 113, no. 12, pp. 2317-2323, 2006.

[21] C. L. Kraus and S. M. Culican, "Nummular keratopathy in a patient with Hyper-IgD Syndrome," Pediatric Rheumatology, vol. 7, article 14, 2009.

[22] M. Albert, E. Beltrán, and L. Martínez-Costa, "Rituximab en queratitis ulcerativa periférica asociada a artritis reumatoide," Archivos de la Sociedad Espanola de Oftalmologia, vol. 86, no. 4, pp. 118-120, 2011.

[23] L. Goodisson, J. T. Bourne, and S. A. Maharajan, "A case of bilateral peripheral ulcerative keratitis following treatment with rituximab," Rheumatology, vol. 49, no. 3, pp. 609-610, 2009.

[24] P. S. Tlucek and D. U. Stone, "Certolizumab pegol therapy for rheumatoid arthritis-associated scleritis," Cornea. In press.

[25] E. B. Devine, R. Alfonso-Cristancho, and S. D. Sullivan, "Effectiveness of biologic therapies for rheumatoid arthritis: an indirect comparisons approach," Pharmacotherapy, vol. 31, no. 1, pp. 39-51, 2011.

[26] C. E. Rabinovich, "Treatment of juvenile idiopathic arthritisassociated uveitis: challenges and update," Current Opinion in Rheumatology, vol. 23, no. 5, pp. 432-436, 2011.

[27] I. Foeldvari, S. Nielsen, J. Kümmerle-Deschner et al., "Tumor necrosis factor- $\alpha$ blocker in treatment of juvenile idiopathic arthritis-associated uveitis refractory to second-line agents: results of a multinational survey," Journal of Rheumatology, vol. 34, no. 5, pp. 1146-1150, 2007.

[28] E. B. Suhler, J. R. Smith, M. S. Wertheim et al., "A prospective trial of infliximab therapy for refractory uveitis: preliminary safety and efficacy outcomes," Archives of Ophthalmology, vol. 123, no. 7, pp. 903-912, 2005.

[29] S. Biester, C. Deuter, H. Michels et al., "Adalimumab in the therapy of uveitis in childhood," British Journal of Ophthalmology, vol. 91, no. 3, pp. 319-324, 2007.

[30] E. Miserocchi, I. Pontikaki, G. Modorati, F. Bandello, P. L. Meroni, and V. Gerloni, "Rituximab for uveitis," Ophthalmology, vol. 118, no. 1, pp. 223-224, 2011.

[31] H. N. Sen, G. Levy-Clarke, L. J. Faia et al., "High-dose daclizumab for the treatment of juvenile idiopathic arthritisassociated active anterior uveitis," American Journal of Ophthalmology, vol. 148, no. 5, pp. 696-e1, 2009.

[32] S. Angeles-Han, T. Flynn, and T. Lehman, "Abatacept for refractory juvenile idiopathic arthritis-associated uveitis-a case report," Journal of Rheumatology, vol. 35, no. 9, pp. 18971898, 2008.

[33] N. Roescher, P. P. Tak, and G. G. Illei, "Cytokines in Sjögren's syndrome: potential therapeutic targets," Annals of the Rheumatic Diseases, vol. 69, no. 6, pp. 945-948, 2010.

[34] X. Mariette, P. Ravaud, S. Steinfeld et al., "Inefficacy of infliximab in primary Sjögren's syndrome: results of the randomized, controlled trial of remicade in primary Sjögren's syndrome (TRIPSS)," Arthritis and Rheumatism, vol. 50, no. 4, pp. 1270-1276, 2004. 
[35] V. Sankar, M. T. Brennan, M. R. Kok et al., "Etanercept in Sjögren's syndrome: a twelve-week randomized, doubleblind, placebo-controlled pilot clinical trial," Arthritis and Rheumatism, vol. 50, no. 7, pp. 2240-2245, 2004.

[36] J. M. Meijer, P. M. Meiners, A. Vissink et al., "Effectiveness of rituximab treatment in primary sjögren's syndrome: a randomized, double-blind, placebo-controlled trial," Arthritis and Rheumatism, vol. 62, no. 4, pp. 960-968, 2010.

[37] L. F. Zapata, L. M. Agudelo, J. D. Paulo, and R. Pineda, "Sjögren keratoconjunctivitis sicca treated with rituximab," Cornea, vol. 26, no. 7, pp. 886-887, 2007.

[38] J. Braun and J. Sieper, "Biological therapies in the spondyloarthritides-the current state," Rheumatology, vol. 43, no. 9, pp. 1072-1084, 2004.

[39] J. Braun, X. Baraliakos, J. Listing, and J. Sieper, “Decreased incidence of anterior uveitis in patients with ankylosing spondylitis treated with the anti-tumor necrosis factor agents infliximab and etanercept," Arthritis and Rheumatism, vol. 52, no. 8, pp. 2447-2451, 2005.

[40] M. Rudwaleit, E. Rodevand, P. Holck et al., "Adalimumab effectively reduces the rate of anterior uveitis flares in patients with active ankylosing spondylitis: results of a prospective open-label study," Annals of the Rheumatic Diseases, vol. 68, no. 5, pp. 696-701, 2009.

[41] I. H. Song, F. Heldmann, M. Rudwaleit et al., "Treatment of active ankylosing spondylitis with abatacept: an open-label, 24-week pilot study," Annals of the Rheumatic Diseases, vol. 70, no. 6, pp. 1108-1110, 2011.

[42] M. D. Schafranski, "Infliximab for reactive arthritis secondary to Chlamydia trachomatis infection," Rheumatology International, vol. 30, no. 5, pp. 679-680, 2010.

[43] A. Edrees, "Successful use of etanercept for the treatment of Reiter's syndrome: a case report and review of the literature," Rheumatology International. In press.

[44] S. Guignard, L. Gossec, C. Salliot et al., "Efficacy of tumour necrosis factor blockers in reducing uveitis flares in patients with spondylarthropathy: a retrospective study," Annals of the Rheumatic Diseases, vol. 65, no. 12, pp. 1631-1634, 2006.

[45] A. Migliore, E. Bizzi, S. Broccoli, and B. Laganà, "Indirect comparison of etanercept, infliximab, and adalimumab for psoriatic arthritis: mixed treatment comparison using placebo as common comparator," Clinical Rheumatology. In press.

[46] C. E. O’Regan, "Errors noted in: re: Migliore A., Bizzi E., Broccoli S. Laganà Indirect comparison of etanercept, infliximab, and adalumimab for psoriatic arthritis: mixed treatment comparison using placebo as common comparator," Clinical Rheumatology. In press.

[47] P. Doctor, A. Sultan, S. Syed, W. Christen, P. Bhat, and C. S. Foster, "Infliximab for the treatment of refractory scleritis," British Journal of Ophthalmology, vol. 94, no. 5, pp. 579-583, 2010.

[48] G. M. Bell, G. Reynolds, and J. D. Isaacs, "Biologic therapies in non-rheumatic diseases: lessons for rheumatologists?" Nature Reviews Rheumatology, vol. 7, no. 9, pp. 507-516, 2011.

[49] F. Hamideh and P. E. Prete, "Ophthalmologic manifestations of rheumatic diseases," Seminars in Arthritis and Rheumatism, vol. 30, no. 4, pp. 217-241, 2001.

[50] T. Hoang-Xuan, C. S. Foster, and B. Rice, "Scleritis in relapsing polychondritis. Response to therapy," Ophthalmology, vol. 97, no. 7, pp. 892-898, 1990.

[51] M. Jabbarvand and M. A. Fard, "Infliximab in a patient with refractory necrotizing scleritis associated with relapsing polychondritis," Ocular Immunology and Inflammation, vol. 18, no. 3, pp. 216-217, 2010.
[52] G. S. Hoffman, M. C. Cid, K. E. Rendt-Zagar et al., "Infliximab for maintenance of glucocorticosteroid-induced remission of giant cell arteritis a randomized trial," Annals of Internal Medicine, vol. 146, no. 9, pp. 621-630, 2007.

[53] M. M. Ahmed, E. Mubashir, S. Hayat, M. Fowler, and S. M. Berney, "Treatment of refractory temporal arteritis with adalimumab," Clinical Rheumatology, vol. 26, no. 8, pp. 13531355, 2007.

[54] A. Bhatia, P. J. Ell, and J. C. W. Edwards, "Anti-CD20 monoclonal antibody (rituximab) as an adjunct in the treatment of giant cell arteritis," Annals of the Rheumatic Diseases, vol. 64, no. 7, pp. 1099-1100, 2005.

[55] A. A. Kubal and V. L. Perez, "Ocular Manifestations of ANCAassociated Vasculitis," Rheumatic Disease Clinics of North America, vol. 36, no. 3, pp. 573-586, 2010.

[56] M. Kontkanen, L. Paimela, and K. Kaarniranta, "Regression of necrotizing scleritis in Wegener's granulomatosis after infliximab treatment," Acta Ophthalmologica, vol. 88, no. 3, pp. e96e97, 2010.

[57] S. R. Taylor, A. D. Salama, L. Joshi, C. D. Pusey, and S. L. Lightman, "Rituximab is effective in the treatment of refractory ophthalmic Wegener's granulomatosis," Arthritis and Rheumatism, vol. 60, no. 5, pp. 1540-1547, 2009.

[58] M. Shunmugam, A. M. Morley, E. Graham, D. D’Cruz, E. O'Sullivan, and R. Malhotra, "Primary Wegener's granulomatosis of the orbital apex with initial optic nerve infiltration," Orbit, vol. 30, no. 1, pp. 24-26, 2011.

[59] J. H. Stone, P. A. Merkel, R. Spiera et al., "Rituximab versus cyclophosphamide for ANCA-associated vasculitis," The New England Journal of Medicine, vol. 363, no. 3, pp. 221-232, 2010.

[60] M. De Menthon, P. Cohen, C. Pagnoux et al., "Infliximab or rituximab for refractory Wegener's granulomatosis: long-term follow-up. A prospective randomised multicentre study on 17 patients," Clinical and Experimental Rheumatology, vol. 29, no. 1, supplement 64, pp. S63-S71, 2011.

[61] V. Kakkassery, S. Mergler, and U. Pleyer, "Anti-TNF- $\alpha$ treatment: a possible promoter in endogenous uveitis observational report on six patients: occurrence of uveitis following etanercept treatment," Current Eye Research, vol. 35, no. 8, pp. 751-756, 2010.

[62] L. L. Lim, F. W. Fraunfelder, and J. T. Rosenbaum, "Do tumor necrosis factor inhibitors cause uveitis? A registry-based study," Arthritis and Rheumatism, vol. 56, no. 10, pp. 32483252, 2007.

[63] D. Fouache, V. Goëb, N. Massy-Guillemant et al., "Paradoxical adverse events of anti-tumour necrosis factor therapy for spondyloarthropathies: a retrospective study," Rheumatology, vol. 48, no. 7, pp. 761-764, 2009.

[64] P. Mitchell, "A systematic review of the efficacy and safety outcomes of anti-VEGF agents used for treating neovascular agerelated macular degeneration: comparison of ranibizumab and bevacizumab," Current Medical Research \& Opinion, vol. 27, no. 7, pp. 1465-1475, 2011.

[65] P. G. Theodossiadis, V. S. Liarakos, P. P. Sfikakis et al., "Intravitreal administration of the anti-TNF monoclonal antibody Infliximab in the rabbit," Graefe's Archive for Clinical and Experimental Ophthalmology, vol. 247, no. 2, pp. 273-281, 2009.

[66] S. Fauser, H. Kalbacher, N. Alteheld, K. Koizumi, T. U. Krohne, and A. M. Joussen, "Pharmacokinetics and safety of intravitreally delivered etanercept," Graefe's Archive for Clinical and Experimental Ophthalmology, vol. 242, no. 7, pp. 582-586, 2004. 


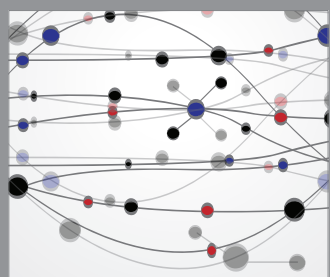

The Scientific World Journal
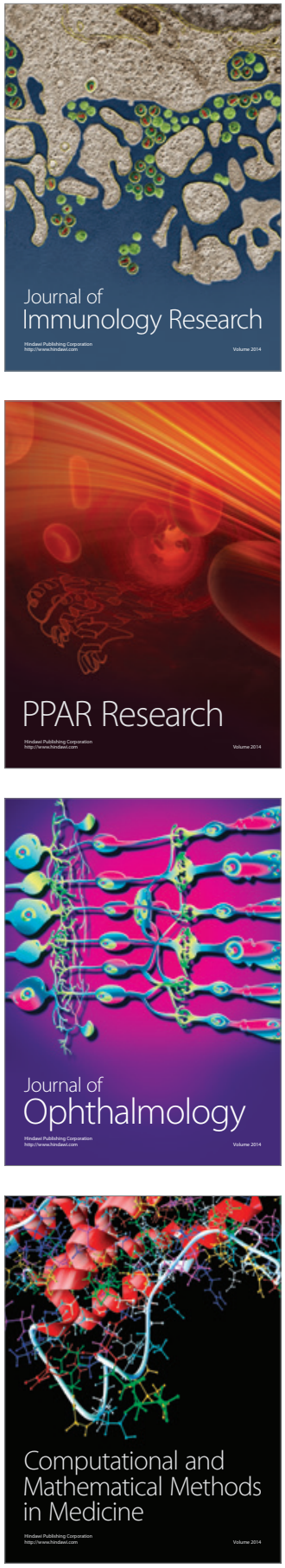

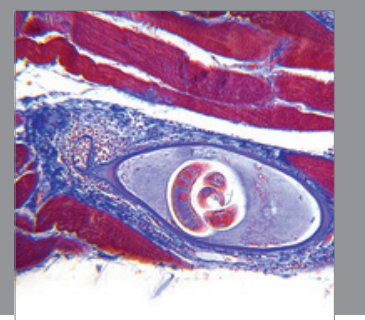

Gastroenterology

Research and Practice
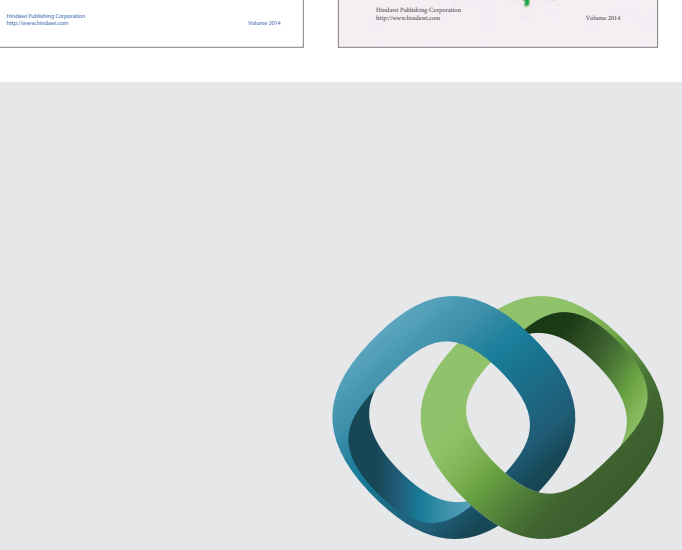

\section{Hindawi}

Submit your manuscripts at

http://www.hindawi.com
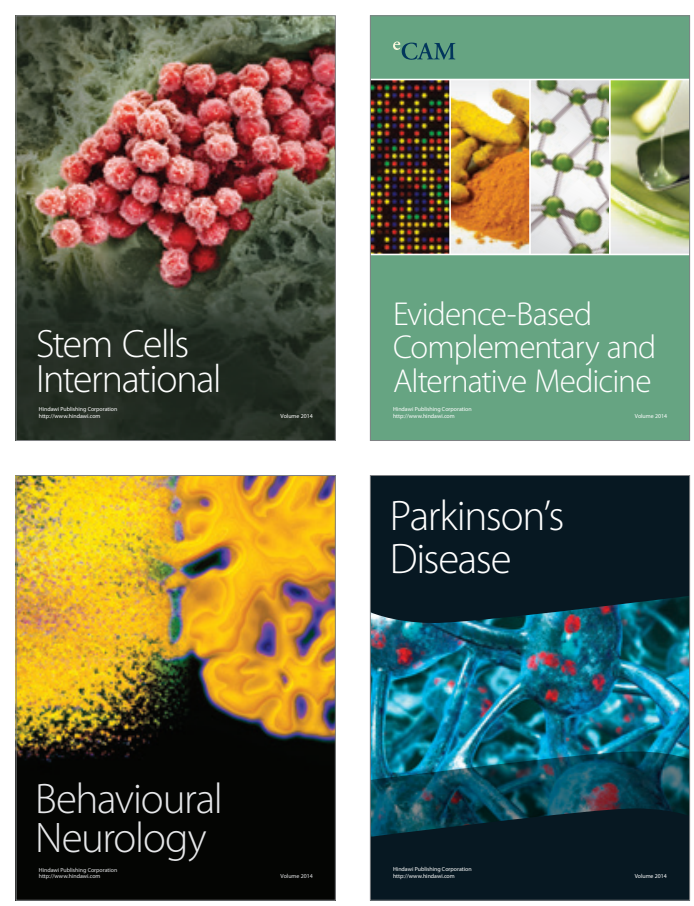

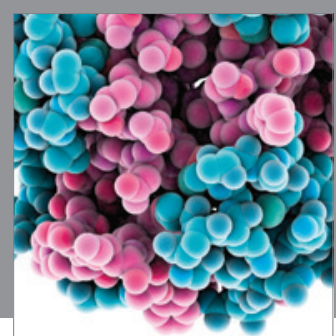

Journal of
Diabetes Research

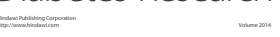

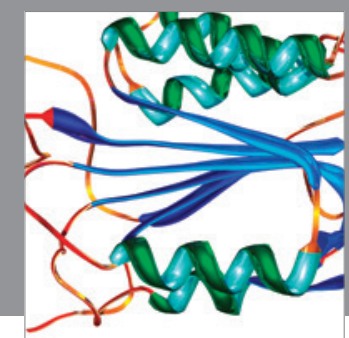

Disease Markers
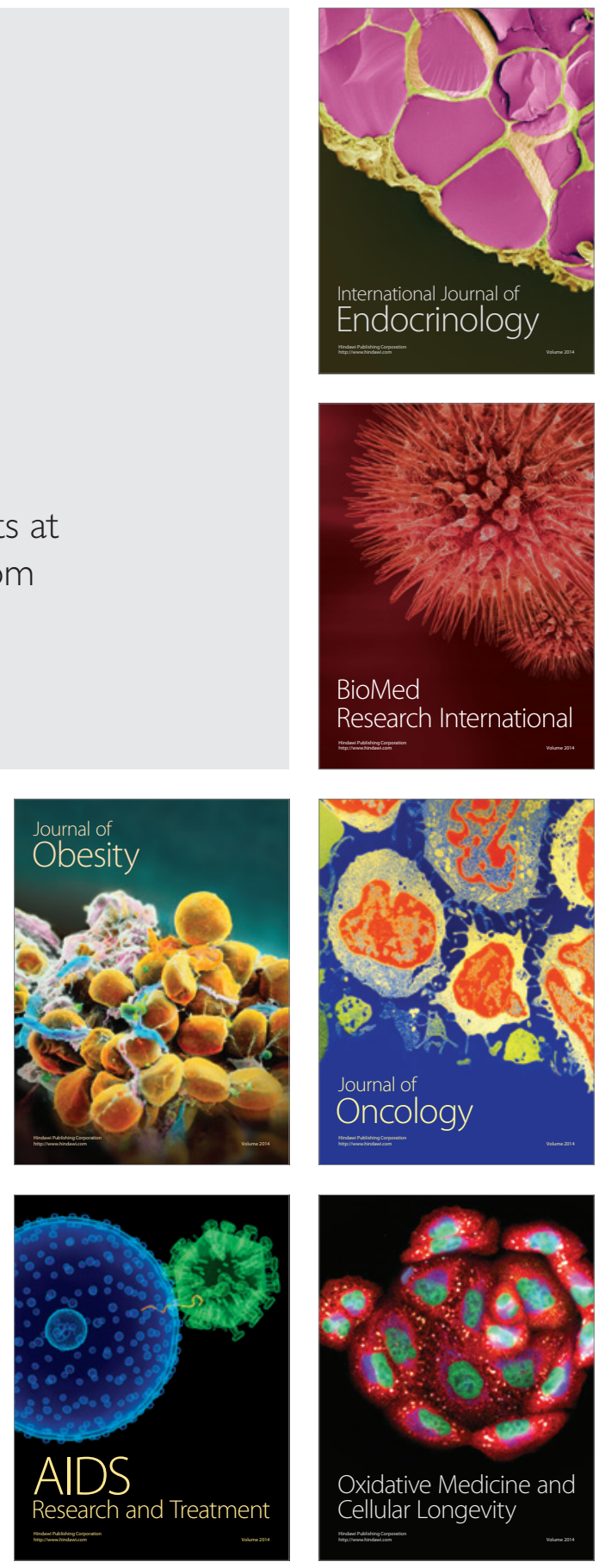